\title{
The Experience of Untapped Potential: Towards a Subjective Temporal Understanding of Work Meaningfulness
}

\section{Giverny De Boeck, Nicky Dries and Hans Tierens}

\section{KU Leuven}

ABSTRACT In this paper, we propose that untapped potential acts as a subjective temporal meaning-making mechanism. Using a two-wave survey design, we examine the relationship between job characteristics, untapped potential, and work meaningfulness in a heterogeneous sample of 542 employees. We found that employees' perceived amount of untapped potential mediates the effects of skill variety, autonomy, and job feedback on work meaningfulness. This mediated relationship was moderated by the valence employees attributed to their untapped potential. Moreover, decreases in the perceived amount of untapped potential over time were related to increases in perceived work meaningfulness. Our research shows that work that allows employees to move beyond the here-and-now by providing opportunities to realize future work selves is experienced as particularly meaningful. We conclude that, if we wish to understand what makes work meaningful for employees in the present, we need to know how it aligns with their self-perceptions in the future.

Keywords: job characteristics, possible self, subjective time, untapped potential, work meaningfulness

\section{INTRODUGTION}

Terkel (1972) once famously wrote that work is a search for daily meaning as well as daily bread, for recognition as well as cash, for astonishment rather than torpor; in short, for a sort of life, rather than a Monday through Friday sort of dying' (p. xi). Research has indeed found that most people attach great importance to the meaningfulness of work - i.e., the feeling that work activities are worthwhile, useful, and valuable, judged in relation to personal ideals or standards (Kahn, 1990; May et al., 2004). Perceived

Address for reprints: Giverny De Boeck, KU Leuven, Department of Work and Organisation Studies, Naamsestraat 69, 3000 Leuven, Belgium (giverny.deboeck@kuleuven.be). 
work meaningfulness has also been shown to relate to numerous positive organizational outcomes such as engagement, job satisfaction, employee wellbeing, performance, and retention (Arnold et al., 2007; Grant, 2007; May et al., 2004; Steger and Dik, 2009).

Traditionally, research has examined work meaningfulness from a work-centric perspective, focusing on how meaningfulness can be managed by manipulating the external work environment (e.g., through job design; Hackman and Oldham, 1975). More recently, however, this managerial approach has been critiqued for disregarding humans' intrinsic need for meaningfulness (Lips-Wiersma and Morris, 2009). Consequently, researchers have begun to explore what makes work meaningful from the perspective of the worker (e.g., Bailey and Madden, 2016). In the worker-centric literature, emphasis is placed on the importance of the self-concept, and in particular on the identity-related mechanisms that underlie employees' meaning-making at work (Pratt and Ashforth, 2003; Rosso et al., 2010).

So far, however, the focus has been exclusively on employees' 'authentic' self in the present. Current research thereby neglects the fact that people draw meaning from multiple selves that can also be temporally located in the past or future (Markus and Wurf, 1987). Arguably, possible selves that represent how people see their potential for the future make up an important part of the self-concept (Markus and Nurius, 1986; Williams et al., 2012). An interview study by Ekman (2013), for instance, showed that fantasies about future potential featured prominently in employees' current perceptions of work meaningfulness. Moreover, in a study of 131 senior HR executives, respondents consistently ranked the ability to realize one's potential as the number one factor that makes jobs most meaningful to employees, placing it before making money and serving others (Mitroff and Denton, 1999).

At the same time, however, the realization of potential at work is by no means selfevident. In practice, work structures often frustrate employees' desire to realize their potential (Berg et al., 2010). As a result, a significant amount of employees risks being left with the feeling that a lot of their potential remains untapped at work - i.e., that a large discrepancy exists between their actual self and their desired future self. In fact, the prevalence of perceptions of untapped potential might explain why a recent survey found that 55 percent out of 19,900 employees across a wide range of industries struggled to find their work meaningful (Schwartz, 2014).

In the present paper, we introduce untapped potential as a subjective temporal experience that can make work more, or less, meaningful from the perspective of the individual employee by functioning as a cognitive bridge between the present and the future. In doing so, we advance understanding of the role of time in work meaningfulness at the micro-level. More specifically, we examine whether the subjective temporal experience of untapped potential mediates the relationship between job characteristics and work meaningfulness, using a two-wave survey design among a large, heterogeneous group of Belgian employees. By simultaneously investigating the influence of factors internal and external to the individual employee, we integrate worker- and work-centric perspectives on meaningful work (Michaelson et al., 2014). In doing so, we address recent calls for more comprehensive models of work meaningfulness (Lips-Wiersma and Morris, 2009; Rosso et al., 2010). 


\section{MEANINGFUL WORK}

Like others before us, we start from the assumption that people's search for meaning is one of the primary motivations in life (Pratt and Ashforth, 2003). Given that we all spend a substantial proportion of our waking hours working, work is a central life domain to look for meaning. Although work is necessary to secure a pay check at the end of the month for much of the working population, people generally also report a strong desire for work that is intrinsically interesting and satisfying (MOW - Meaning of Work International Research Team, 1987). In this respect, it is important to distinguish between the possible meanings attached to work - i.e., the type of meaning individuals ascribe to work (e.g., work as a pay check versus a higher calling) - and work meaningfulness - i.e., the amount of significance work holds for individuals (Rosso et al., 2010).

Broadly stated, the literature on meaningful work can be categorized as either workcentric or worker-centric in focus (Michaelson et al., 2014; Wrzesniewski et al., 2003).

\section{The Work-Centric Perspective on Work Meaningfulness}

Arguably, meaningful work 'always requires some degree of objective autonomy to pursue one's subjective aspirations' (Michaelson et al., 2014, p. 85). Researchers who study meaningful work from a work-centric perspective argue that organizations should provide and manage meaning (Lips-Wiersma and Morris, 2009). The work-centric stream of research has focused mainly on identifying those elements in the work context that act as sources of (or barriers to) meaningfulness (Rosso et al., 2010), such as job design (e.g., Grant, 2007; Hackman and Oldham, 1975) or leadership styles (e.g., Arnold et al., 2007; Bono and Judge, 2003). For example, Grant (2007) recently developed a conceptual model highlighting the importance of the relational architecture of jobs - i.e., whether and to what extent work allows employees to make a prosocial impact and have contact with beneficiaries - as a source of meaningful work.

In the present study, we focus specifically on the five job characteristics identified by Hackman and Oldham (1975) in their seminal Job Characteristics Model (JCM). These include the degree to which a job requires the use of different skills (skill variety); requires the completion of a 'whole' piece of work (task identity); has a significant impact on the lives of others (task significance); allows workers to choose their work schedule and procedures (autonomy); and provides workers with direct information about the effectiveness of their performances (job feedback). Together, these dimensions determine the motivating potential of a job. According to Hackman and Oldham (1975), jobs with high motivating potential transform the performance of work into a rewarding experience for employees by creating feelings of meaningfulness, responsibility for work outcomes, and knowledge of results. In particular, skill variety, task significance, and task identity are argued to influence employees' perceived work meaningfulness in the JCM.

Empirical research supports a positive relationship between the job characteristics identified in the JCM and perceptions of work meaningfulness (e.g., Fried and Ferris, 1987; Humphrey et al., 2007; May et al., 2004). The meta-analysis conducted by Fried and Ferris (1987), for example, showed a consistently positive relationship between each of the job characteristics and perceived work meaningfulness. Based on existing 
evidence of job design as an important predictor of meaningful work (Rosso et al., 2010), we hypothesize that:

Hypothesis 1: Skill variety, task identity, task significance, autonomy, and job feedback are positively related to perceptions of work meaningfulness, such that the higher employees rate their jobs on these five dimensions, the more work meaningfulness they will perceive.

\section{The Worker-Centric Perspective on Work Meaningfulness}

At the same time, Rosso et al. (2010) have concluded that 'perceptions of meaningfulness must necessarily travel through the self' (p. 15). In contrast to the work-centric perspective, worker-centric researchers approach meaningful work in a more agentic way, assuming that employees are active creators of meaning who naturally engage in meaning-making (Lips-Wiersma and Morris, 2009). Here, work meaningfulness is perceived as a subjective experience that depends on what employees themselves bring into work (Chalofsky, 2003; Pratt and Ashforth, 2003). This implies that any type of job can be experienced as meaningful. This point is illustrated by research showing that even people who perform so-called 'dirty work' - i.e., work that is devalued by society because of its physically, socially, or morally repulsive nature, such as refuse collection or exotic dancing - can find their work highly meaningful (e.g., Ashforth and Kreiner, 1999; Wrzesniewski and Dutton, 2001).

More specifically, worker-centric researchers perceive work meaningfulness as the result of a sense-making process during which employees interpret their work within broader cognitive self-schemata (Pratt and Ashforth, 2003). A recent interview study, for example, found that 135 employees in 10 different occupations framed 'moments of meaningfulness' at work in the broader context of their personal lives (e.g., their family or community; Bailey and Madden, 2016). The self plays a pivotal role in the process of sense-making that shapes people's experience of work meaningfulness (Pratt and Ashforth, 2003). This follows from the fact that work behaviour is not only instrumental, but also motivated by people's desire to self-express (Shamir, 1991).

The self is understood here in terms of the self-concept. The self-concept refers to the dynamic and multiple cognitive self-representations or 'identities' that people have (e.g., woman, mother, manager), which are hierarchically organized according to their relative importance (Callero, 1985; Markus and Wurf, 1987; Stryker and Burke, 2000). Especially work that is congruent with one's self-concept, allowing employees to enact their 'true' authentic self, is argued to be meaningful to employees (Pratt and Ashforth, 2003; Rosso et al., 2010).

In their review, Rosso et al. (2010) identify three authenticity mechanisms: selfconcordance, identity affirmation, and personal engagement. Self-concordance refers to individuals' pursuit of goals that are consistent with their own interests and core values (Sheldon and Elliot, 1999). Bono and Judge (2003) found, for example, that followers of transformational leaders perceived their work to be more meaningful when they pursued short-term work goals that were aligned with their personal beliefs and interests. Identity affirmation refers to the processes through which work verifies, affirms, or activates valued 
personal identities (Rosso et al., 2010). Elsbach (2003), for example, showed how managers display portable artefacts (e.g., photos of their kids) in workspaces to affirm their identity. Personal engagement refers to the physical, cognitive, and emotional employment and expression of the self at work. Kahn (1990), for example, found that employees who felt they could be fully present - physically, cognitively, and emotionally - in their role performance, perceived their work as particularly meaningful.

To date, however, scholars have been overlooking the temporal dimension of identity when arguing for the relevance of the self in people's quest for meaningful work. Research on work meaningfulness tends to assume that people only have one 'true' self that is situated in the present time. The self-concept, however, consists of multiple identities that can be situated in either the past, the present, or the future (Albert, 1977; Cross and Markus, 1991; Markus and Nurius, 1986). Particularly interesting in this respect are possible selves - i.e., representations of who an individual desires to become (desired/ ideal selves), is afraid of becoming (feared selves), and feels that he or she should become (ought selves) (Markus and Nurius, 1986). Possible selves reflect how individuals think about their potential in the future, which can be remarkably different from thoughts about the self in the present (Markus and Nurius, 1986).

People attach great importance to beliefs about their future potential. Recent experimental research has shown, for example, that people see their future potential as a meaningful component of the self, weighing it heavily in evaluations of themselves - much more so than in their evaluations of others, whom they tend to judge based on past behaviour (Williams and Gilovich, 2008; Williams et al., 2012). Even though possible selves have not (yet) been validated by (social) experience, they can exert a considerable influence on individuals' current motivations and affective states (Markus and Nurius, 1986; Myers, 2009). Ibarra (1999), for example, described how 'provisional' selves motivated consultants and investments bankers to experiment with new roles by selectively imitating the behaviours of role models in their organizations (e.g., adopt a director's style of interacting with clients).

Because of their significant impact on people's work experience beyond aspects of the self in the here-and-now (Markus and Nurius, 1986), we argue that research on identity-based mechanisms of work meaningfulness should also pay attention to the role of people's possible selves in the future. In the following section, we will argue that one way to do this is by examining employees' experience of untapped potential at work.

\section{THE EXPERIENGE OF UNTAPPED POTENTIAL AS A SUBJEGTIVE TEMPORAL MEANING-MAKING MEGHANISM}

Etymologically, potential derives from the Latin 'potens', meaning capable. In his Metaphysics, Aristotle described potentiality (dunamis) as belonging to matter, with the capacity to transform into a different and more completed state, and distinguished it from actuality - the matter's realization into an actual form (energeia) (Cohen, 2016). The contrast between what is possible and what is actual also features strongly in more contemporary conceptualizations of potential. Frisby and Braden (1992), for example, 
define potential as 'the modifiability of unobservable structures that have not as yet become actual, or exist in possibility, capable of development in actuality' (p. 283).

Kuo (2011) argued that it is the human desire for 'becoming' that opens up a space of possibilities. By using their imagination, people move beyond the present and anticipate possible scenarios in the future, creating a mental distance between where they are now (actual selves) and where they want to go in the future (desired selves) (Kearney, 1988; Kuo, 2011). Although desired selves can pertain to any domain of life, the focus here lies on future work selves, reflecting people's hopes and aspirations for the future in relation to work (Strauss et al., 2012). When employees succeed to connect their present work activities to their future work selves, this creates a sense of purpose, motivating employees to approach the desired end-states that their future work selves entail (Markus and Nurius, 1986; Strauss et al., 2012; Waterman, 2004).

At the same time, Oettingen (2012) has noted that simply indulging on future work selves as positive fantasies is not enough to ignite change. Instead, she argues that people need to experience a discrepancy which follows from mentally contrasting the future self with the present reality. According to self-discrepancy theory (Higgins, 1987), people are generally motivated to reduce discrepancies. More specifically, actual-ideal discrepancies motivate approach behaviour in employees, such that they will try to reduce this discrepancy through, for example, pursuing challenging goals (Brendl and Higgins, 1996; Higgins, 2000). When such discrepancy reduction is successful, the actual self and the ideal self are congruent, leading to positive outcomes. When discrepancy reduction fails, however, this will have negative effects. Moreover, the greater the magnitude of the self-discrepancy, the more negative the outcomes will be (Higgins, 1987, 2000).

Untapped potential can be defined as the discrepancy resulting from the intertemporal comparison between individuals' actual selves in the present and the desired selves toward which they hope to progress in the future (Albert, 1977). The realization of potential, then, involves reducing the discrepancy between the actual and desired future selves (Fernando and Chowdhury, 2015; Nucci, 2004). In line with Higgins' (1987) theoretical logic, we assume that employees will strive to realize their potential. When employees are in the process of realizing their potential at work, they are in fact actualizing in the present what was merely a possibility in the past, thereby moving closer to their ideal self in the future. In doing so, past, present, and future become interconnected, and work is transformed into a meaningful process of self-development (Baumeister and Vohs, 2002).

In other words, when an employee perceives a small amount of untapped potential at work, he or she will have 'a sense of where $[\mathrm{s}]$ he is going and that $[\mathrm{s}]$ he is living to realize future possibilities' (Clark, 1997, p. 89), which will increase perceptions of work meaningfulness. In contrast, when an employee perceives a large amount of untapped potential at work, a significant actual-ideal discrepancy arises. Consequently, we expect employees with large amounts of untapped potential to perceive their work as less meaningful (Bailey and Madden, 2015; Shepherd and Williams, 2018; Twenge et al., 2003). Based on the above, we hypothesize the following:

Hypothesis 2: The amount of untapped potential at work, experienced by an employee, is negatively related to perceptions of work meaningfulness such that employees who 
experience having a higher amount of untapped potential will perceive less work meaningfulness.

In addition to the perceived amount of untapped potential, employees' experiences of untapped potential are also characterized by high or low expectations of success, activated by the process of mental contrasting (Oettingen, 2012). Like the metaphor of viewing one's glass as half full or half empty, untapped potential can be seen either positively - as a chance for future development - or negatively - as a missed opportunity. This complexity is captured by the concept of valence, i.e., the 'positivity or negativity of an event' (Brendl and Higgins, 1996, p. 96). Rather than constituting a fixed, inherent property of an experience, valence is the result of individual, subjective appraisal (Brendl and Higgins, 1996). People evaluate an experience in a positive or a negative manner, depending on whether it is associated with expected future gains (opportunities) or losses (barriers), respectively (Meister et al., 2014).

The positive or negative valence associated with untapped potential will thus be related to whether or not employees expect to realize their potential in the future. Employees can, for instance, expect to realize their untapped potential in the future when they have just started a new job, or see their current position as a stepping stone towards a more fitting role. In this case, untapped potential represents a potential future gain for employees and will be appraised positively. Conversely, employees can also have low expectations of realizing their untapped potential at work, when they feel hindered (for instance, by their direct supervisor) to prove what they are capable of. In this case, untapped potential is associated with barriers that are not expected to dissipate in the near future, and will be appraised negatively.

According to fantasy realization theory (Oettingen, 2012), mental contrasting will stimulate goal pursuit when people's expectations of success are high, while it will foster goal disengagement when people's expectations of success are low. Oettingen et al. (2001) have shown, for example, that, after mentally contrasting positive fantasies of a happy ending with an interpersonal conflict in the present reality, people only made plans to solve the conflict when expectations of success were high, but not when expectations of success were low. Similarly, a recent study found evidence that mental contrasting of a desired future with a present reality led to better creative performance when it was accompanied by positive rather than neutral feedback on people's creative potential (Oettingen et al., 2012). Therefore, we hypothesize the following moderation effect:

Hypothesis 3a: If untapped potential has a negative valence, this will intensify the negative relationship between the perceived amount of untapped potential and perceived work meaningfulness.

Hypothesis $3 b$ : If untapped potential has a positive valence, this will buffer the negative relationship between the perceived amount of untapped potential and perceived work meaningfulness.

Employees' perceived amount of untapped potential has also been linked to job characteristics, most notably to opportunities present in the work context to utilize and develop one's knowledge and skills (Waterman, 2004). Inspired by Csikszentmihalyi's (2003) 'flow' theory, 
Vogt (2005) argued that organizations can help employees realize their potential through job design. More specifically, he suggested that managers should optimally challenge employees by providing them with rich and complex tasks, the autonomy to decide how to accomplish these tasks, and direct feedback on their performance. Similarly, Berg et al. (2010) argued that jobs with high autonomy allow employees to accomplish better alignment with their desired selves. A recent study showed, for example, that employees who successfully increased the autonomy, task identity, and skill variety in their jobs, felt they could make better use of their skills at work (Lu et al., 2014). In contrast, when jobs are designed such that skill variety, task identity, task significance, autonomy, and job feedback are limited, there is no room, nor incentive for employees to use their abilities or express their desired self (Kahn, 1990; Mottaz, 1981; Schacht, 1971). Based on the above, we hypothesize:

Hypothesis 4: Skill variety, task identity, task significance, autonomy, and job feedback will be negatively related to the amount of untapped potential at work experienced by an employee, such that the higher employees rate their jobs on these five dimensions, the lower will be the amount of untapped potential they perceive.

Combining Hypotheses 1, 2, and 4, we propose the following mediation hypothesis:

Hypothesis 5: The positive relationship between skill variety, task identity, task significance, autonomy, job feedback, and work meaningfulness will be mediated by the perceived amount of untapped potential.

Finally, the realization of potential requires that employees repeatedly assess whether or not they are making progress towards their future work selves (Scheffler, 2010). In this respect, ideal selves in the future function as self-referent criteria for employees to monitor their own actions and outcomes (Markus and Nurius, 1986; Nucci, 2004; Ryff, 1991). People will thus evaluate the extent to which their potential remains untapped based on how much progress they are making towards a desired end-state. Since progress requires movement, employees will only feel that they are realizing their potential when they succeed in realizing its constitutive possibilities with the passage of time. The realization of potential is thus a dynamic process of movement over time (Bodnar, 2012; Kovacs, 1982). Moreover, as people constantly reformulate their desired end-states (Kuo, 2011), the realization of potential is inherently episodic and expandable, with new potentials arising as older ones are realized (Scheffler, 2010). Consequently, the realization of potential should be defined as an ongoing process that can only be completed in the continuous undertaking of the activity (Hinchliffe, 2004; Leclerc et al., 1998).

Past research has found that a sense of progress has a profound positive impact on employees' inner work experiences (Amabile and Kramer, 2007, 2011). In fact, scholars have claimed that a sense of progress towards desired goals is vital to the experience of meaningful work (Rosso et al., 2010). Translating this logic to the work context, we argue that the experience of work meaningfulness requires employees to be engaged in work activities that enable them to actualize their potential within a bounded temporal space (i.e., their career from today until their expected retirement age). With the passing of 
time, some employees will feel that they are approaching their ideal future selves, whereas others will find themselves stuck or drifting further away from what they desire(d) to become (Ryff, 1991). Therefore, we hypothesize the following:

Hypothesis 6: Changes in the amount of untapped potential at work are related to changes in perceptions of work meaningfulness, such that employees will experience less work meaningfulness at a later point in time if their perceived amount of untapped potential has increased over time prior to this point.

In addition to changing the perceived amount of untapped potential, the passage of time can also alter the valence that people ascribe to their experience of untapped potential. This proposition is in line with earlier research that claims that the valence attached to an experience does not only vary across individuals, but also varies over time. As Brendl and Higgins (1996) note, 'even the same person might find an event positive at one time and negative at another time' (p. 96). Especially the situation in which employees assess the valence of the experience of untapped potential negatively at $\mathrm{T} 2$ - meaning that the valence has either changed from positive to negative, or has remained negative over time - is likely to be problematic. Rather than making progress, employees will feel that they are going backwards or that they are stagnating in a negative experience which, in turn, will have a negative impact on their perceptions of work meaningfulness. This brings us to the following hypothesis:

Hypothesis 7: The valence of the experience of untapped potential is related to changes in perceptions of work meaningfulness, such that employees will experience less work meaningfulness at a later point in time if the experience of untapped potential has a negative (as compared to a positive) valence at that time.

\section{METHODS}

\section{Design}

The study was set up using a two-wave survey design in which the focal variables were measured at two time points, with a one and a half year time lag in between. The time lag was deliberately chosen to allow for changes over time in our focal variables (Maggetti et al., 2012). Both the experience of untapped potential at work and perceived work meaningfulness can be expected to fluctuate on a medium-term basis, with people re-evaluating their work situation every few months (Taris and Kompier, 2014). All constructs were measured identically at both times using validated scales.

A quantitative survey design was chosen because we were mainly interested in finding empirical evidence for the relationship between job characteristics, employees' experience of untapped potential, and perceived work meaningfulness. In addition, one open-ended question (described in detail in the Measures section further down) was also included in the survey to explore the meanings that people ascribed to their experiences of untapped potential (Fink, 2003). The resultant qualitative data were used to evaluate the valence of respondents' experiences of untapped potential (see Table I). 


\section{Sample}

At T1, we set out to draw a stratified sample mirroring the demographic characteristics of the working population in Flanders (Belgium) in terms of gender, age, educational level, and contract type. We, the three authors together with two research assistants, composed a panel of potential respondents over a period of three months' time in two phases: First, we contacted people from our direct social networks and, after receiving their consent, included these into the panel. Subsequently, we selectively extended our initial sample by asking people from our direct social networks to suggest others within their own networks that were underrepresented in our initial sample (in particular, low-educated workers and workers older than 40).

In total, the panel consisted of 1,028 workers active in various functions, organizations and sectors. After sending out the survey in Qualtrics by email, 759 workers completed the survey within the predetermined period of 45 days, yielding a response rate of 74 per cent. After cases with missing data were eliminated, the final sample consisted of $542 \mathrm{em}$ ployees $\left(\mathrm{N}_{\mathrm{T} 1}\right)$, of which 45 per cent were male and 55 per cent were female. The average age of respondents was 37.13 ( $\mathrm{SD}=12.30) ; 7$ per cent of respondents were 24 or younger, 54 per cent were between 25 and 40, 16 per cent between 41 and 49, and 23 per cent were 50 or older. The majority of respondents held a bachelor's or master's degree (66 per cent), and were employed full-time (79 per cent). Except for educational level, which showed an inverted distribution compared to the Flemish working population, sample characteristics were in line with the reference population as reported by the Flemish Policy Research Center for Work and Social Economy, i.e., 52.4 per cent were male; 8.3 per cent were 24 or younger, 40.7 per cent were between 25 and 40, 26.4 per cent were between 41 and 49, and 24.7 per cent were 50 or older; 40.1 per cent were highlyeducated; 72 per cent were employed full-time (Vanderbiesen, 2016).

Sample heterogeneity was further demonstrated by additional sample characteristics: 50 per cent of respondents worked for a private-sector organization (as compared to 33 per cent working for a public-sector organization and 17 per cent for a mixed public-private sector or 'other' type of organization), and 10 per cent of respondents held a managerial position (as compared to 47 per cent professionals, 21 per cent clerical and service workers, 15 per cent skilled workers, and 7 per cent unskilled workers). The size of respondents' employing organizations ranged from fewer than 10 employees to over 5,000 employees, with organizations being active across 28 economic sectors including, but not limited to, construction, health care, education, and finance.

Attrition analyses. All respondents with complete data at $\mathrm{T} 1$ were invited to participate in the T2 survey one and a half years later, yielding a response rate of 32 per cent $\left(\mathrm{N}_{\mathrm{T} 2}\right.$ $=174$ ). Between T1 and T2, 54 respondents (31 per cent) had changed jobs, of which 38 (22 per cent) had also changed employers. To rule out bias resulting from systematic dropout of respondents between the first and second wave of data collection, we performed attrition analyses. More specifically, we investigated whether T1 respondents who had also completed the T2 survey were different from $\mathrm{T} 1$ respondents who had not participated at T2 in terms of demographic characteristics, untapped potential, and 
work meaningfulness. No significant differences were found for gender $\left(\chi^{2}(1, N=542)\right.$ $=0.60, \mathrm{p}=0.44)$, age $(\mathrm{t}(334)=0.40, \mathrm{p}=0.69)$, educational level $\left(\chi^{2}(2, \mathrm{~N}=542)=5.06\right.$, $\mathrm{p}=0.08)$, or contract type $\left(\chi^{2}(2, \mathrm{~N}=542)=.62, \mathrm{p}=0.73\right)$, nor for the percentage of untapped potential $(\mathrm{t}(318)=-.16, \mathrm{p}=0.87)$ or perceived work meaningfulness $(\mathrm{t}(334)=1.09, \mathrm{p}=0.28)$. These results suggest a random dropout pattern between $\mathrm{T} 1$ and $\mathrm{T} 2$ and thus a low risk of systematic attrition bias in our data.

\section{Procedure}

The research was framed more broadly as aiming to investigate the work experience of Belgian employees. In the introduction, we emphasized that our main interest was to gain insight into workers' personal beliefs, stated that there were no right and wrong answers to any of the questions in the survey, and explicitly guaranteed respondent anonymity. Participants were incentivized to participate in our research by drawing their attention to the opportunity to win a multimedia voucher with a value of 15 Euro after survey completion. In order to avoid social desirability bias (Podsakof et al., 2003), respondents were asked to tick a box to confirm that they would answer the questions of the survey honestly on the first screen of the survey. Finally, to anticipate the issue of common method variance (CMV), we followed Podsakoff et al.'s (2003) procedural recommendations in the design of our survey. We measured variables using different scale formats and anchors (scales never exceeded 10 items), avoided double-barrelled and ambiguous items, and counterbalanced item order.

\section{Measures}

Perceived work meaning fulness. Perceived work meaningfulness was measured using the sixitem scale developed by May et al. (2004). This scale was developed as an extension of Spreitzer's (1995) validated three-item subscale of psychological empowerment which proved to have good convergent and discriminant validity (Kraimer et al., 1999). Since its development, this scale has been used successfully to measure work meaningfulness in diverse samples, including workers of an American insurance company $(\alpha=0.90$; May et al., 2004) and employees of a multinational petrochemical company $(\alpha=0.92$; Olivier and Rothmann, 2007). A sample item is 'I feel that the work I do on this job is valuable'. Respondents rated all items on a five-point Likert scale ranging from one (strongly disagree) to five (strongly agree). The Cronbach's Alpha for the scale was 0.94 both at $\mathrm{T} 1$ and $\mathrm{T} 2$.

Job characteristics. Autonomy, skill variety, task identity, task significance, and job feedback were measured using the 10-item scale developed by Idaszak and Drasgow (1987) based on Hackman and Oldham's (1975) JCM. This scale was checked for measurement accuracy in the original paper, with reported fidelity coefficients of above 0.80 for each of the five characteristics (Idaszak and Drasgow, 1987). A sample item is 'The job gives me a chance to use my personal initiative or judgment in carrying out the work' (autonomy). Respondents rated all items on a seven-point Likert scale, ranging from one (totally incorrect) to seven (totally correct). The Cronbach's Alpha for the full 10-item scale was 0.79 at $\mathrm{T} 1$ and 0.80 at T2. At the level of individual job characteristics - which 
were measured using five pairs of two items (Idaszak and Drasgow, 1987) - we found Spearman-Brown reliability coefficients between 0.55 and 0.77 at $\mathrm{T} 1$ and between 0.58 and 0.80 at $\mathrm{T} 2$.

Amount of untapped potential. Since we were interested in capturing employees' personal experience of untapped potential, we decided to develop a single item specifically catered towards this end, flanked by an open textbox (see below in the section on valence). We asked respondents to indicate - on a slide bar from 0 to 100 per cent - the percentage that, in their opinion, best reflected the extent to which their potential was untapped in the area of work at the time of survey administration. The approach of using single-item measurements has been demonstrated to work particularly well for constructs that require a global evaluation (a typical example being job satisfaction), and/or complex constructs that would require a seemingly endless list of items to cover all facets potentially relevant to respondents, which would subsequently need to be weighed according to individual values or priorities (e.g., quality of life; Fuchs and Diamantopoulos, 2009).

Valence of untapped potential. Directly below the quantitative untapped potential item we provided a textbox, instructing respondents to write a brief explanation of why they had selected that specific percentage of untapped potential. To make sure that we captured respondents' idiosyncratic experiences of untapped potential at work, in the instructions above the textbox we emphasized that there were no right or wrong answers, but that we just wanted them to 'think aloud' about how they came to select the percentage that they did. We recoded the qualitative data into a quantitative valence measure using content analysis.

Content coding of the valence of untapped potential. Before performing our main quantitative analyses, we first recoded the qualitative textbox data into a categorical measure capturing the valence of respondents' experiences of untapped potential (for a similar approach, see Amabile et al., 2005). To this end, the authors conducted a directed content analysis (Hsieh and Shannon, 2005) of all 542 descriptions of employees' experiences of untapped potential. Building on Brendl and Higgins's (1996) principles of judging valence - in particular, the principle of goal supportiveness - we coded responses into a categorical valence variable with a positive and a negative category.

Responses were categorized as positive or negative depending on whether work was judged to facilitate or impede the realization of potential, respectively. This categorization is consistent with our theoretical differentiation between untapped potential as a future gain (possibilities) versus a future loss (missed opportunities). Positively valenced experiences typically included references to various job resources (e.g., challenging work, learning opportunities), allowing respondents to make active use of their skills and knowledge. Negatively valenced experiences, on the other hand, focused predominantly on barriers that hindered respondents in realizing their potential. Although some respondents mentioned internal barriers (e.g., personal capacities), most statements concerned external barriers related to their job and the broader organization (e.g., work overload, regulations). 
Because some textbox responses could not be unequivocally classified as positive or negative - typically containing multiple statements of which one or more could be classified as positive and the others as negative - we added a third, 'ambivalent' valence category.

To infer the reliability of our categorization of respondents' accounts of untapped potential into positive, negative and ambivalent experiences, we calculated inter-rater reliability - i.e., the degree to which the categorization could be reproduced by another coder (Krippendorff, 2004). To this end, the second author categorized 50 randomly selected cases into the three aforementioned valence categories. The percentage of agreement was 82 per cent and the Cohen's Kappa was 0.76, indicating solid inter-rater reliability (McHugh, 2012). Categorizations were compared among coders and disagreements were discussed until consensus was reached.

Of the responses, 192 (35.4 per cent) were categorized to have a negative valence, 261 (48.2 per cent) were categorized to have a positive valence, and 89 (16.4 per cent) were categorized to have an ambivalent valence. The percentage of untapped potential was skewly distributed across the valence categories (Table I): 104 negative experiences

Table I. Proportion of Respondents Coded as Having Negatively, Positively, and Ambivalently Valenced Experiences of Untapped Potential, as a Function of Their Perceived Amount of Untapped Potential at T1 $\left(\mathrm{N}_{\mathrm{T} 1}=542\right)$

\begin{tabular}{|c|c|c|c|c|}
\hline & & \multicolumn{3}{|c|}{ Amount of Untapped Potential } \\
\hline & & $0 \%-20 \%$ & $20 \%-30 \%$ & $30 \%-97 \%$ \\
\hline \multirow{6}{*}{$\begin{array}{l}\text { Valence of } \\
\text { Untapped } \\
\text { Potential }\end{array}$} & Positive & $149(27 \%)$ & $55(10 \%)$ & $57(11 \%)$ \\
\hline & & \multicolumn{3}{|c|}{$\begin{array}{l}\text { e.g., '90\% fulfilled because I receive many opportunities to learn. My work is definitely } \\
\text { not yet a routine. Besides, they give me the chance to maximally apply things that I } \\
\text { am learning on a daily basis or have learned in the past, also during my studies, } \\
\text { which gives me the feeling that my potential is utilized'. (Woman, 25, junior HR } \\
\text { generalist) }\end{array}$} \\
\hline & \multirow[t]{2}{*}{ Negative } & $49(9 \%)$ & $39(7 \%)$ & $104(19 \%)$ \\
\hline & & \multicolumn{3}{|c|}{$\begin{array}{l}\text { e.g., 'A lot of my qualities and knowledge are untapped. For example, I have a good } \\
\text { knowledge of marketing with which nothing is done. Sometimes, in my opinion, my } \\
\text { supervisors just act without knowledge, where they would do well to utilize the } \\
\text { knowledge of their subordinates. Sometimes they even do the opposite [of what I would } \\
\text { recommend if I were asked] which makes me wonder at those times what I am doing. } \\
\text { I sometimes have to do repetitive administrative work which I do not want to do at } \\
\text { all. I want to grow. I am capable of more'. (Woman, 34, staff officer in education) }\end{array}$} \\
\hline & \multirow[t]{2}{*}{ Ambivalent } & $42(8 \%)$ & $27(5 \%)$ & $20(4 \%)$ \\
\hline & & \multicolumn{3}{|c|}{$\begin{array}{l}\text { e.g., 'I utilize much of my knowledge and talents in performing my job, but due to work } \\
\text { pressure and lack of time some of my ideas cannot develop. Especially in project } \\
\text { development, the implementation of my creativity in different domains is limited. } \\
\text { Also, in my opinion, I could add more value in the area of PR, but I limit my } \\
\text { involvement there because it requires too much time and energy'. (Woman, } 48 \text {, } \\
\text { educational programme counsellor) }\end{array}$} \\
\hline
\end{tabular}

Note: Values represent number (and proportion) of respondents for each combination of amount and valence of untapped potential; Chi-squared test of Independence: $\chi^{2}=66.61 ; \mathrm{df}=4 ; \mathrm{p}<0.01$. 
(54.2 per cent) fell in the range of 30-97 per cent of untapped potential (in contrast to only 57 positive experiences), while 149 positive experiences (57.1 per cent) fell in the range of $0-20$ per cent of untapped potential (in contrast to only 47 negative experiences). Although ambivalent experiences were spread out a bit more evenly across the different ranges, the distribution was also skewed in a direction similar to that of the distribution of positive experiences: 42 cases (47.2 per cent) fell in the range of $0-20$ per cent of untapped potential.

Control variables. Because sociodemographic characteristics such as gender, age, educational level, and contract type (full-time or part-time) have been found to affect employees' perceived work meaningfulness (Grouden and Jose, 2014), we controlled for these variables in our regression analyses.

\section{Analyses}

Data analyses were performed in two phases, corresponding to the two sections reported in the Results. In the first phase of our analysis, a cross-sectional stepwise regression model was tested based on the T1 data alone, to examine whether people's experience of untapped potential predicted perceived work meaningfulness above and beyond the effects of job characteristics. In the model, skill variety, task identity, task significance, autonomy, and job feedback were entered as predictors (step 2) after first entering the control variables (step 1). In a next step, untapped potential was entered, adding first the percentage measure (step 3), and then the categorical valence variable resulting from our qualitative analysis (step 4). In step 5, the interaction terms between the amount and valence of untapped potential were entered. Due to multicollinearity, however, we restricted model five by omitting the insignificant moderation parameters (step 6; final model).

In the second phase of analysis, change variables were calculated by computing difference scores between T1 and T2 for each quantitative variable. In the change model, we sequentially added the control variables (step 1), the change scores for skill variety, task identity, task significance, autonomy, and job feedback (step 2), the change scores for the percentage of untapped potential (step 3), and the valence of the experience of untapped potential at T2 (step 4; final model).

\section{RESULTS}

Table II shows the intercorrelations between the study variables at T1 and T2. In line with our hypotheses, the table shows significant negative correlations between job characteristics and the percentage of untapped potential, and significant positive correlations between job characteristics and perceived work meaningfulness. As expected, the percentage of untapped potential was also negatively correlated with perceived work meaningfulness. 


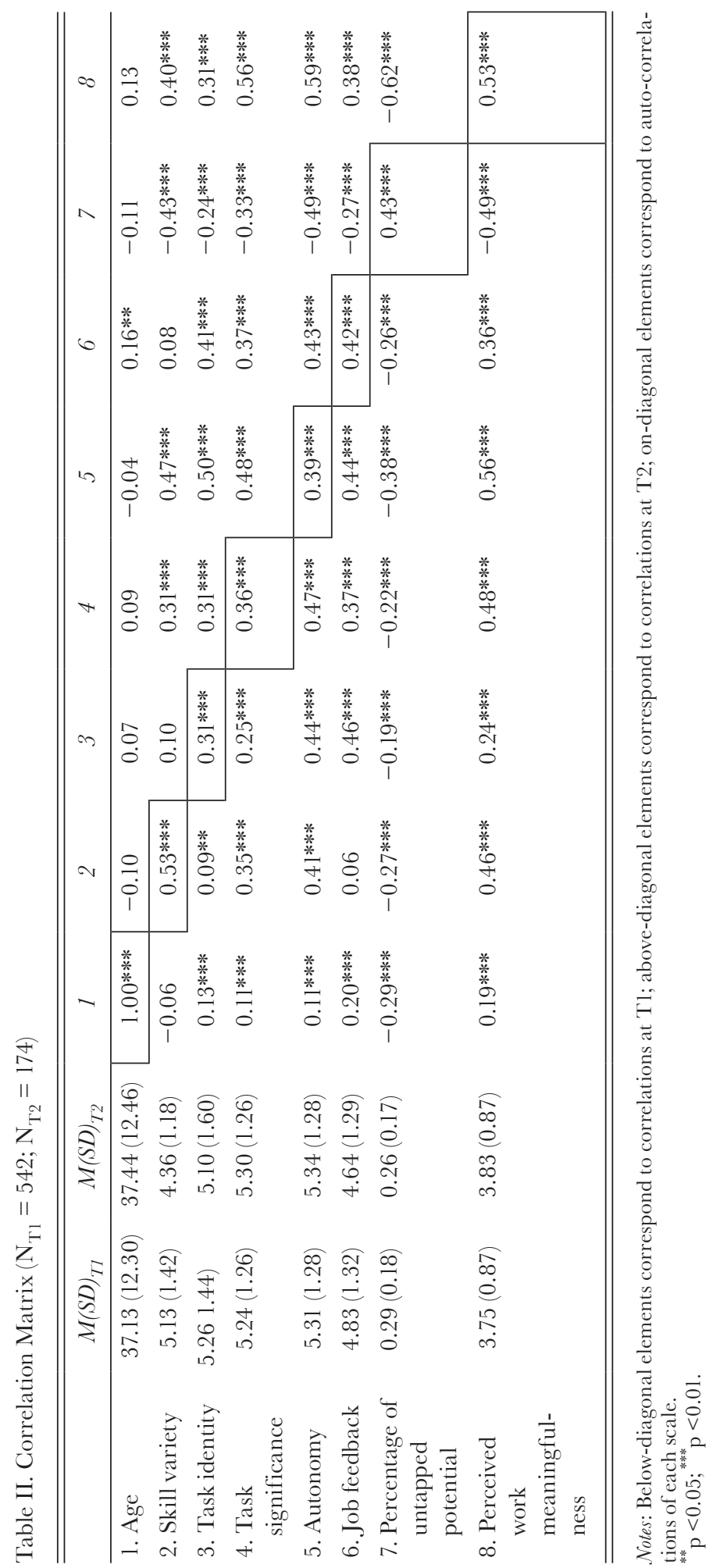

(C) 2018 John Wiley \& Sons Ltd and Society for the Advancement of Management Studies 


\section{Gross-Sectional Model: Job Characteristics, Untapped Potential, and Work Meaningfulness (T1)}

The results of the cross-sectional regressions analyses on perceived work meaningfulness (Hypotheses 1-5) are reported in section A of Table III. In step 1, we observed that all control variables, except for contract type, were significant such that women, older employees, and highly-educated individuals scored higher on work meaningfulness compared to men, younger employees, and low-educated respondents. In step 2, the results demonstrated that all job characteristics, except for task identity, had highly significant, positive effects on work meaningfulness: The more skill variety, task significance, autonomy, and job feedback respondents experienced in their jobs, the more they perceived their work to be meaningful. With the exception of task identity, these results thus supported Hypothesis 1.

Step 3 showed that the percentage of untapped potential - transformed into a value ranging from 0 to 1 - had a significant negative effect on perceived work meaningfulness $(\beta=-1.21, \mathrm{p}<0.01)$ : Respondents who indicated higher percentages of untapped potential experienced less work meaningfulness. This finding supported Hypothesis 2. In step 4, we also observed a significant effect of valence such that perceived work meaningfulness was lower when untapped potential was experienced negatively as compared to the referent category of ambivalent valence. No significant effect was found, however, for positive valence. In step 5, we added the interaction terms between the amount and valence of untapped potential. However, due to inflated standard errors caused by multicollinearity, the effects of untapped potential became statistically insignificant. Therefore, we restricted model 5 (Table III) by omitting the parameters causing multicollinearity, including the moderation effect of positive valence. The absence of a loss of model fit $(\mathrm{F}=0.27 ; \mathrm{p}=0.85)$ implied that positive valence did not moderate the relation between untapped potential and work meaningfulness. As shown in the final model, the effect of the amount of untapped potential was moderated by the valence of the experience such that its negative effect on perceived work meaningfulness was stronger when people had a negative (difference in $\beta=-0.62, \mathrm{p}<0.01$ ) compared to an ambivalent or positive experience of untapped potential $(\beta=-0.72, \mathrm{p}<0.01)$. Hence, while Hypothesis 3 a was supported by these results, Hypothesis $3 \mathrm{~b}$ did not seem to hold.

Finally, we wanted to test whether the relationship between the job characteristics and perceived work meaningfulness was mediated by employees' amount of untapped potential. Therefore, we first analysed the direct effects of the five job characteristics on employees' amount of untapped potential. The results of our cross-sectional regression analyses on the percentage of untapped potential are reported in section B of Table III. We found a significant, negative effect of skill variety, autonomy and job feedback on the amount of untapped potential: Employees who indicated to have more skill variety, autonomy, and job feedback in their jobs perceived lower amounts of untapped potential. No significant direct effects were found, however, for task identity and task significance. Hence, Hypothesis 4 was only partially supported. As shown in section B of Table III, the model showed good fit with the data, explaining 24 per cent of variance in the percentage of untapped potential $(\mathrm{F}=16.14$, df $=11, \mathrm{p}<0.01)$. 


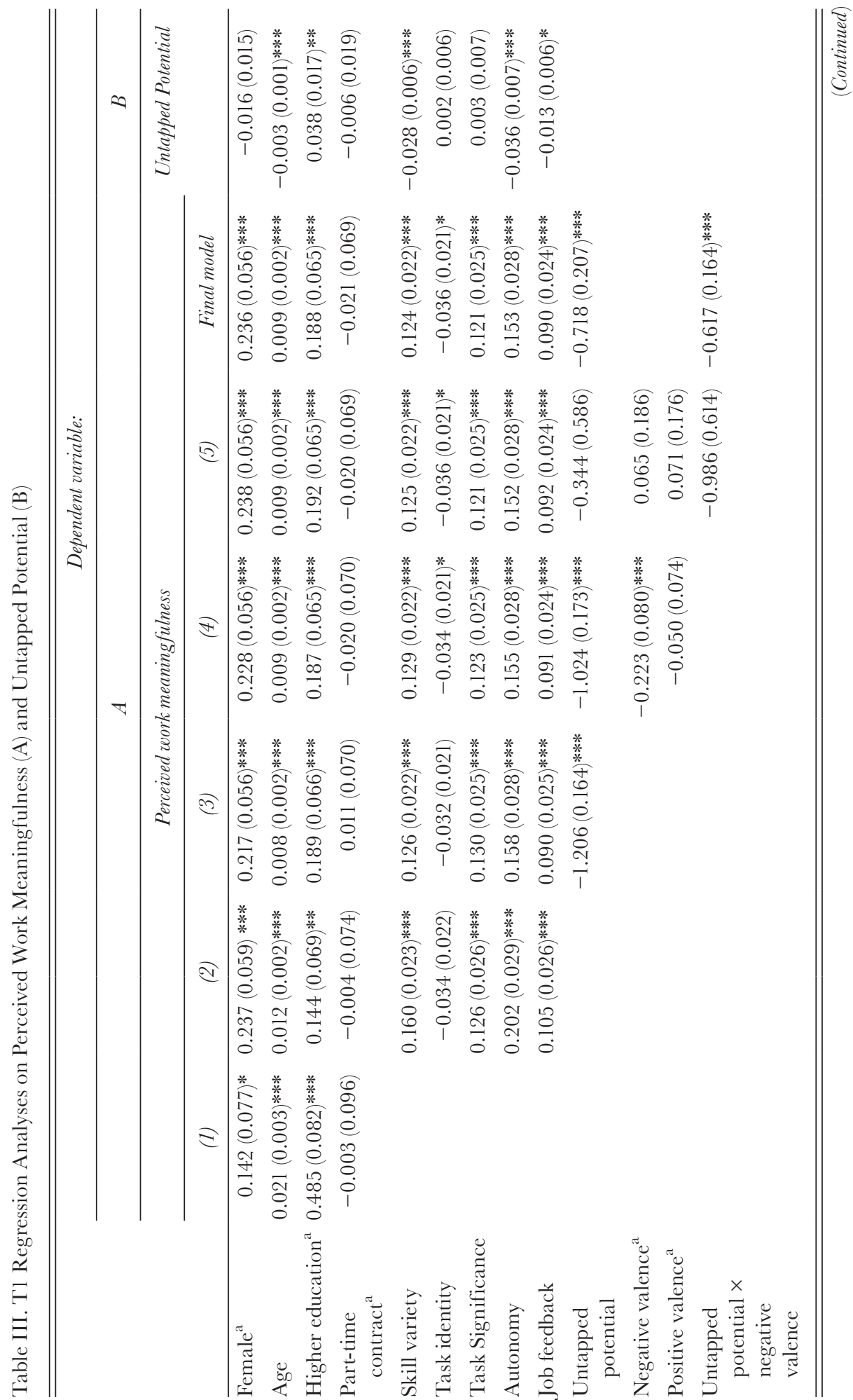

C 2018 John Wiley \& Sons Ltd and Society for the Advancement of Management Studies 


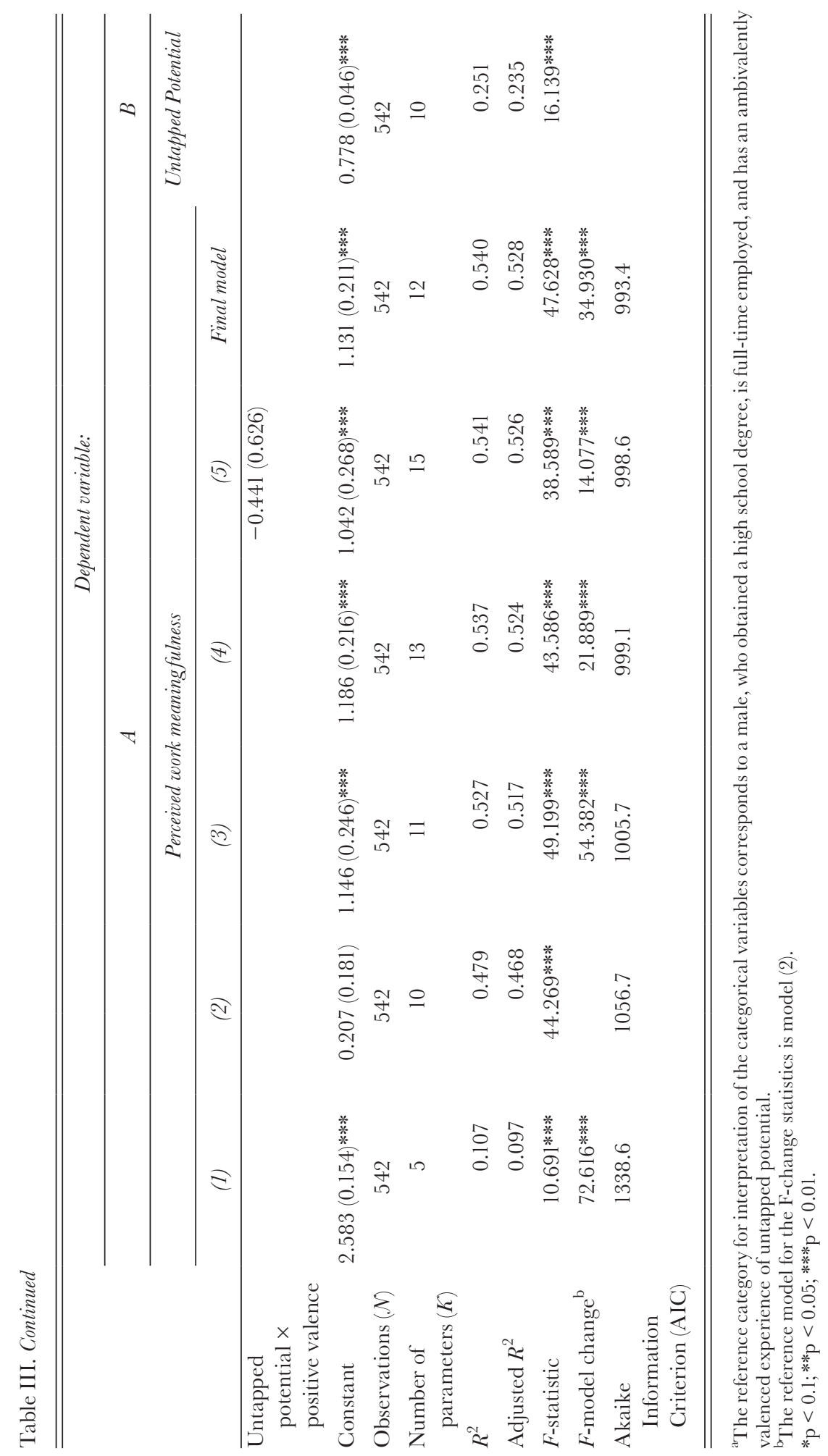


In a second step, we returned to section A of Table III to inspect whether, after adding the 'potential' variable in step 3, there were changes in the magnitude of the regression coefficients of the job characteristics. We found that the regression coefficients decreased for skill variety, autonomy, and job feedback in step 3 compared to step 2 which supported a partial mediation effect by employees' amount of untapped potential. This was not the case, however, for task identity and task significance. Hence, our results only partially supported Hypothesis 5.

Overall, the cross-sectional regression model showed very good fit with the data. It explained 54 per cent of variance in work meaningfulness when controlled for model complexity $(\mathrm{F}=47.63 \mathrm{df}=13, \mathrm{p}<0.01)$, representing a significant increase compared to the baseline model $(\mathrm{F}$ model change $=34.93 \mathrm{df}=2, \mathrm{p}<0.01)$.

\section{Change Model: Changes in Job Characteristics, Untapped Potential, and Work Meaningfulness (T1-T2)}

In this section, we explain the results of our regression analyses on the change in perceived work meaningfulness between $\mathrm{T} 1$ and $\mathrm{T} 2$ as reported in Table IV. In step 1, we observed that, of the control variables, only age $(\beta=-0.01, \mathrm{p}<0.01)$ and educational level $(\beta=-0.21, \mathrm{p}<0.01)$ had a significant effect on changes in perceived work meaningfulness: Older and more highly-educated individuals experienced larger decreases in work meaningfulness compared to younger and less highly-educated respondents. In step 2, the results showed that changes in task significance and autonomy between T1 and $\mathrm{T} 2$ had a significant, positive effect on changes in perceived work meaningfulness. No significant effects on changes in perceived work meaningfulness were found, however, for changes in skill variety, task identity, and job feedback.

In the third and final regression step, Hypothesis 6 and 7 were tested. Changes in the percentage of untapped potential over time closely resembled a normal distribution centred around a mean of zero, ranging from -67 to +65 per cent. We found that increases in the amount of untapped potential between $\mathrm{T} 1$ and $\mathrm{T} 2$ had a significant, negative effect $(\beta=-0.87, \mathrm{p}<0.01)$ on changes in perceived work meaningfulness. Significant results were also found for the valence of untapped potential: A negative experience at T2 - in 58 per cent of cases, the result of a change from a positive or ambivalent experience, in 42 per cent of cases the continuation of a negative experience at $\mathrm{T} 1$ - was associated with a decrease in work meaningfulness over time $(\beta=-0.33, \mathrm{p}<0.05)$ relative to a positive experience at T2. An ambivalent experience at T2 had a non-significant, negative effect on change in meaningfulness $(\beta=-0.13, \mathrm{p}=\mathrm{ns})$. Hence, we found support for both Hypothesis 6 and Hypothesis 7.

The change model, as well, showed very good fit with the data. It explained 44 per cent of the variance in changes in perceived work meaningfulness between T1 and T2 when controlled for model complexity $(\mathrm{F}=8.83$, $\mathrm{df}=13, \mathrm{p}<0.01)$, representing a significant increase compared to the baseline model ( $\mathrm{F}$ model change $=4.65 \mathrm{df}=3, \mathrm{p}<0.01)$. 
Table IV. Regression Analysis on the Change in Perceived Work Meaningfulness between T1 and T2

\begin{tabular}{|c|c|c|c|c|}
\hline & \multicolumn{4}{|c|}{ Dependent variable: } \\
\hline & \multicolumn{4}{|c|}{$\Delta$ Perceived work meaning fulness } \\
\hline & (1) & (2) & (3) & Final model \\
\hline Female $^{\mathrm{a}}$ & $-0.036(0.140)$ & $-0.034(0.114)$ & $-0.081(0.113)$ & $-0.101(0.112)$ \\
\hline Age & $-0.011(0.003)^{* * *}$ & $-0.009(0.005)$ & $-0.006(0.005)$ & $-0.006(0.005)$ \\
\hline Higher education $^{\mathrm{a}}$ & $-0.207(0.162)^{* * *}$ & $-0.048(0.133)$ & $-0.078(0.131)$ & $-0.090(0.131)^{* *}$ \\
\hline Part-time contract ${ }^{\mathrm{a}}$ & $0.057(0.188)$ & $0.233(0.154)$ & $0.221(0.151)$ & $0.201(0.150)$ \\
\hline$\Delta$ Skill variety & & $0.059(0.046)$ & $0.016(0.047)$ & $0.015(0.047)$ \\
\hline$\Delta$ Task identity & & $0.036(0.032)$ & $0.033(0.031)$ & $0.034(0.031)$ \\
\hline$\Delta$ Task significance & & $0.129(0.043)^{* * *}$ & $0.132(0.042)^{* * *}$ & $0.122(0.042)^{* * *}$ \\
\hline$\Delta$ Autonomy & & $0.256(0.046)^{* * * *}$ & $0.233(0.046)^{* * *}$ & $0.223(0.046)^{* * *}$ \\
\hline$\Delta$ Job feedback & & $-0.028(0.041)$ & $-0.043(0.041)$ & $-0.037(0.040)$ \\
\hline $\begin{array}{l}\Delta \text { Untapped } \\
\text { potential }\end{array}$ & & & $(0.313)^{* * *}-0.873$ & $-0.751(0.314)^{* *}$ \\
\hline $\begin{array}{l}\text { Ambivalent valence } \\
(\mathrm{T} 2)^{\mathrm{a}}\end{array}$ & & & & $-0.134(0.123)$ \\
\hline $\begin{array}{l}\text { Negative valence } \\
(\mathrm{T} 2)^{\mathrm{a}}\end{array}$ & & & & $-0.328(0.134)^{* *}$ \\
\hline Constant & $0.580(0.306)^{*}$ & $0.414(0.253)$ & $0.304(0.251)$ & $0.433(0.254)^{*}$ \\
\hline Observations $(\mathcal{N})$ & 174 & 174 & 174 & 174 \\
\hline $\begin{array}{l}\text { Number of } \\
\text { parameters }(K)\end{array}$ & 5 & 10 & 11 & 13 \\
\hline$R^{2}$ & 0.033 & 0.388 & 0.416 & 0.438 \\
\hline Adjusted $R^{2}$ & 0.000 & 0.347 & 0.373 & 0.388 \\
\hline$F$-statistic & 0.948 & $9.342 * * *$ & $9.569 * * *$ & $8.833^{* * *}$ \\
\hline$F$-model change ${ }^{\mathrm{b}}$ & $18.808^{* * *}$ & & $7.772 * * *$ & $4.652 * * *$ \\
\hline $\begin{array}{l}\text { Akaike Information } \\
\text { Criterion (AIC) }\end{array}$ & 446.6 & 376.9 & 370.7 & 368.3 \\
\hline
\end{tabular}

${ }^{\text {a }}$ The reference category for interpretation of the categorical variables corresponds to a male, who obtained a high school degree, is full-time employed, and has a positively valenced experience of untapped potential;

${ }^{\mathrm{b}}$ The reference model for the F-change statistics is model (2).

$* \mathrm{p}<0.1 ; * * \mathrm{p}<0.05 ; * * * \mathrm{p}<0.01$

\section{DISGUSSION}

Using a two-wave survey design, we examined employees' experience of untapped potential at work as a subjective temporal meaning-making mechanism in the relationship between job characteristics and work meaningfulness. Our results showed that employees' experience of untapped potential was an important predictor of work meaningfulness, which partially mediated the positive effects of job characteristics - in particular, 
skill variety, autonomy, and job feedback - on work meaningfulness. Both the cross-sectional and the change model proved to be particularly powerful, explaining 54 per cent and 44 per cent of the variance in (changes in) employees' perceived work meaningfulness, respectively. These effect sizes well exceed the upper benchmark of 0.26 for medium effect sizes in management research (Bosco et al., 2015). Overall, our study seems to have successfully captured part of the complexity of work meaningfulness by integrating both work-centric and worker-centric perspectives. In doing so, we answer recent calls for more comprehensive models of meaningful work (Lips-Wiersma and Morris, 2009; Rosso et al., 2010).

\section{Theoretical Implications}

The main theoretical contribution of this study lies in evidencing the importance of subjective time to our understanding of work meaningfulness. Although scholars have been arguing for the central role of time in understanding work experiences for some years (Roe, 2008; Sonnentag, 2012), time has remained a neglected topic in management research more generally, and in studies on meaningful work in particular (Bailey and Madden, 2015). Our study shows that work is meaningful to employees to the extent that it allows them to realize their potential. More specifically, when employees realize their potential at work, they perceive a connection between their present work activities and personally desired futures, making work a more meaningful experience (Baumeister and Vohs, 2002; Baumeister et al., 2013).

The importance of subjective time for the experience of work meaningfulness is supported by previous research. Bailey and Madden (2015), for example, have investigated the role of time from a sociological perspective - as a social construction - in three particular occupations: stonemasons, refuse collectors, and academics. Their results showed that people in these occupations found work meaningful when they succeeded to transcend the here-and-now by making temporal connections to the past (e.g., continuing the use of historic methods) or future (e.g., contributing to the development of next generations) at the macro-societal level. Similarly, Bunderson and Thompson (2009) also found that zookeepers perceived their day-to-day work activities to be highly meaningful by framing these as necessary for the future conservation of endangered species.

Our findings extend this recent research by demonstrating the importance of subjective time for meaningful work, from a psychological perspective, at the micro-level of individual employees. Our results show that employees working in a variety of functions, occupations, and sectors can transcend time via their idiosyncratic experiences of untapped potential at work. More specifically, when employees perceive a low amount of untapped potential, their actual self in the present is congruent with their ideal self in the future, allowing for intertemporal connections. In this case, employees perceive their present work activities as an opportunity to use and further develop their skills. In contrast, when employees perceive a large amount of untapped potential, there is a strong actual-ideal self-discrepancy in which the present is felt to be disconnected from a personally meaningful future. Our results show that such a discrepancy is especially detrimental when employees also valence their experience of untapped potential negatively. 
Employees who imagine their future in terms of continued routine and repetition can be said to feel trapped in an 'eternal present' (Stolorow, 2003, p. 160).

The second contribution of the present study is that it provides deeper insight into the relationship between job characteristics and work meaningfulness. More specifically, our results showed significant positive effects of skill variety, task significance, autonomy, and job feedback on work meaningfulness, that - with the exception of task significancewere partially mediated by employees' perceived amount of untapped potential. The absence of a mediation effect for task significance can be explained by the fact that, contrary to skill variety, autonomy, and job feedback which are strongly focused on the self (i.e., enabling the use and further development of personal capacities), task significance is more outward-focused, representing the degree to which a job impacts others outside the self (Grant, 2007; Hackman and Oldham, 1975).

Although these job characteristics have been critiqued from a worker-centric perspective for being ways to 'manage' meaning for employees (Lips-Wiersma and Morris, 2009), our findings hint at an alternative and more constructive interpretation. More specifically, we argue that job characteristics should be viewed as opportunity structures that need to be present in the work environment for employees to be able to 'make' work a personally meaningful experience (Waterman, 2004). In this way, our study reconciles the work-centric and worker-centric perspectives by showing how both are in fact complementary in nature (Michaelson et al., 2014).

Our third contribution lies in illustrating that work meaningfulness is susceptible to change over time. More specifically, we found that work meaningfulness can both increase and decrease over time, and that these changes were influenced by decreases and increases in the perceived amount of untapped potential, respectively. In particular, employees who perceived less untapped potential at T2 compared to T1, perceived their work to be more meaningful at T2. In line with research on the positive impact of progress (Amabile and Kramer, 2007, 2011), it seemed that employees who successfully realized more potential over the course of one and a half years, also succeeded in transforming work into something more meaningful.

Moreover, the valence of untapped potential also impacted changes in work meaningfulness. Employees who negatively valenced their perceived amount of untapped potential at T2 reported larger decreases in work meaningfulness over time. This means that both employees whose situation deteriorated (i.e., went from a positive or ambivalent to a negative experience) and employees whose situation stagnated (i.e., remained in a negative experience) perceived their work to be significantly less meaningful at T2 compared to T1. The finding that work can become less meaningful over time even though little appears to have changed in people's negative experience is interesting, because this signals that standing still can also have severe negative effects. More specifically, employees who remain stuck in a work situation in which they do not expect to realize their potential in the future might experience work as a 'waste' of time - a temporal experience which has been identified in previous research on the experience of work meaninglessness (Bailey and Madden, 2015). At the same time, we could not find a significant effect for ambivalent valence at T2. This means that, when employees change to or stagnate in a situation in which they still partly perceive opportunities to realize their potential at 
work (ambivalent valence), this will not have an impact on work meaningfulness at T2 compared to change to or stagnation in a positively valenced experience.

Fourth, with this study, we are the first to conceptualize potential from the perspective of the employee as involving future-oriented self-thoughts. In doing so, we contribute to current research on employee potential in two ways. First, we provide a complementary perspective to the dominant managerial approach found in talent management research which focuses narrowly on 'high-potential' employees - those identified by management as an organization's likely future leaders (e.g., Silzer and Church, 2009). Second, we cast a new light on the notion of self-actualization (Maslow, 1943). This concept features prominently in the literature on positive functioning at work (e.g., Spreitzer et al., 2005), and on meaningful work in particular (e.g., Chalofsky, 2003). Rather than identifying the realization of potential or 'self-actualization' as an important work value (Rosso et al., 2010), we highlight the inherent temporal nature of this experience. In doing so, we also link the understanding of potential more firmly to existing theories on identity (e.g., Markus and Nurius, 1986), self-discrepancy (e.g., Higgins, 1987), and temporal imagination (e.g., Oettingen, 2012).

\section{Limitations and Avenues for Future Research}

As is the case for all single-standing studies, our study was not without limitations. First of all, we measured the amount of untapped potential with a single item asking employees to indicate the extent to which their potential was currently untapped at work on a scale ranging from 0 to 100 per cent. Although the use of single items is generally contested in management research, a single-item measure can be preferable over a traditional, multi-item measure when measuring highly complex, multifaceted constructs (Fuchs and Diamantopoulos, 2009). A global measure allows respondents to consider all relevant aspects and idiosyncratically weigh these into one single rating. Thereby, the risk of misrepresentation due to, for example, the use of a limited number of items or fixed weighting procedures - as is typically the case with multi-item measures - is minimized (Nagy, 2002). Given the complexity of untapped potential, we consciously chose to use a single-item measure to capture employees' holistic experience of untapped potential at work.

Although beyond the scope of the present study, we acknowledge that this measure did not allow us to capture the effects of the ever-expanding nature of potential. As argued earlier in this paper, what people believe they are maximally capable of can change over time. Both at T1 and T2, we deliberately focused our measurement on the present, asking employees to rate the degree to which their potential was untapped at work at that specific moment in time. This formulation takes into account possible changes in the total amount of potential over time and thereby minimizes the sensibility of changes in the percentage of untapped potential to expansion of the total amount of potential over time. However, researchers interested in disentangling changes in the relative versus the total amount of untapped potential might explore alternative measurements that make this distinction explicit.

Second, although we categorized employees' experiences of untapped potential in terms of valence, this measure was only constructed after data collection, based on 
the responses to the additional, open-ended survey question. As a result, it is a rough measure and should be interpreted with caution in the data analyses. To come to a deeper understanding of employees' experience of untapped potential at work, future research should focus on collecting richer qualitative data. Researchers could, for instance, conduct interviews to gain insight into how employees make intertemporal connections, precisely. Especially the investigation of extreme cases - i.e., employees who are realizing either close to all or none of their potential - would be interesting to further explore in relation to, for example, notions such as the 'eternal present' (Stolorow, 2003). Such micro-level insights would further complement the dominant macro-level perspective on the role of subjective time in work meaningfulness as found in sociological studies (e.g., Bailey and Madden, 2015) and anthropological studies (e.g., Sharma, 2014).

Third, given that we collected data from the same respondents at the same point in time, common method variance (CMV) is a potential issue in our cross-sectional analyses (Podsakoff et al., 2003). Therefore, upon completion of the data collection, we followed Podsakoff et al.'s (2003) statistical recommendations to test for CMV. A set of confirmatory factor analyses were performed to check the discriminant validity of our measures and rule out potential common method bias. For the measures at $\mathrm{T} 1$, a seven-factor model $\left(\chi^{2}(99)=362.92 ; \mathrm{CFI}=0.95, \mathrm{SRMR}=0.04\right)-$ modelling the five job characteristics, untapped potential, and work meaningfulness as separate factors - was found to exhibit better fit than a single-factor model, where all items were set to load on only one factor $\left(\Delta \chi^{2}(20)=867.83 ; \mathrm{p}<0.01\right)$. Adding a common method factor led to non-convergence of the model. Similar results were obtained for the measures at T2. The seven-factor model $\left(\chi^{2}(99)=177.28\right.$; CFI $=0.96$, SRMR $=0.04)$ showed better fit than the single factor model $\left(\Delta \chi^{2}(20)=390.44 ; \mathrm{p}<0.01\right)$. Again, the common method factor model did not converge. Based on these results, we tend to believe that the influence of CMV in the measurement model was limited in our study.

A fourth and fifth limitation of our research design involves its restrictions in terms of sample and objective time. Although our sample was broadly representative on a number of demographics, individuals were not randomly selected into the sample and therefore the sample might not be fully representative of the Belgian working population. Moreover, we measured our variables only at two moments in time, over a period of one and a half years. Sample attrition over time reduced our sample from 542 to 174 respondents. Although our two-wave survey design did allow us to measure changes, future studies might aim to sample a larger group of respondents more frequently over a longer period of time to increase the likelihood that changes in meaningfulness will occur for a larger subset of respondents. A larger group of respondents at T2 would also allow researchers to investigate more systematically the effects of 'staying put' versus changing jobs or organizations, on changes in both the experience of untapped potential and perceived work meaningfulness. In addition, this type of design would allow for studying trajectories over time, such as the honeymoon/hangover effect - i.e., increases in positive work attitudes immediately after a job change that are later countered by a decline (Boswell et al., 2005). 


\section{Practical Implications}

Since 35.4 per cent of employees in our sample have a negative experience of untapped potential, we can infer that many people feel hindered in the realization of their potential at work. This finding is problematic because many employees share the fantasy that work can only be meaningful when it allows them to realize their potential (Ekman, 2013). As a result, a substantial part of the workforce is at risk of perceiving their work as meaningless (Schwartz, 2014). At the same time, our findings also illustrate that organizations can promote work meaningfulness by offering employees the opportunity to realize their potential at work via job design. More specifically, organizations should design jobs in such a way that employees can use different skills, have discretion over how and when to perform their work tasks, and receive regular feedback on their performance. In addition, organizations can also directly boost work meaningfulness for employees by making clear how their jobs impact others (Grant, 2007).

Moreover, organizations can also develop interventions targeted at the realization of potential, taking into account employees' temporal cognitions related to their personal pasts and futures. For example, direct supervisors can initiate regular conversations with employees to gauge whether their work is still aligned with their individual aspirations (e.g., as part of the annual appraisal process), to make sure that they are not feeling stuck at work. Organizations can also help employees perceive their work activities within a broader time frame by, for example, asking them to consciously reflect about their future work selves (Strauss et al., 2012). Employees' future work selves, in turn, can guide the design of specific development programs with personal learning goals. When followed up over time, initiatives such as these can enable feelings of continuous progress in employees (Amabile and Kramer, 2007, 2011).

Nevertheless, employers should also be cautious not to stretch employees too far in terms of their personal capacities and energy to prevent exhaustion (Courtright et al., 2014). The results of our study hint that this problem is evident in a small group of employees (9 per cent) who appraised very low amounts of untapped potential - between 0-20 per cent - in a negative way. Closer inspection of their explanations revealed that these employees lived in an 'extended' present, making references to how constant time pressure caused them to work hastily from task to task without time to make plans for the future (Kamp et al., 2011). This finding indirectly challenges the idea that people always aspire to realize their potential to the fullest - a phenomenon that was termed 'the fantasy of limitless potential' by Ekman (2013).

In practice, employees' desire to realize their potential often clashes with the fact that jobs are designed in function of organizational needs (e.g., efficiency) which are not necessarily aligned with employees' aspirations (Berg et al., 2010). Nevertheless, we also want to acknowledge employees' agency in this matter. From an employee perspective, our study shows that the worst thing is to be in a work situation that does not allow one to realize his or her potential. The most drastic way for employees to change this situation is by leaving it. However, for many employees quitting their jobs might not be an option. Therefore, we have two suggestions: First, because prevention is better than cure, we advise employees to consciously reflect on their future aspirations prior to applying for jobs, 
and bring them up with recruiters and potential future supervisors such as to achieve a realistic job preview. Second, if employees already find themselves in jobs that hinder the realization of their potential, they can experiment with job crafting techniques and try to reshape their current job in a way that puts their skills and knowledge to better use (Wrzesniewski and Dutton, 2001). Employees could, for example, take on additional tasks voluntarily to incorporate work aspects that are currently missing in their jobs (Berg et al., 2010).

To conclude, our findings support the idea that people's experience of time is, to a certain extent, externally controlled (Bergmann, 1992; Sharma, 2014). Sharma (2014), for example, showed how workers' time experience is actually structured and controlled by the surrounding institutional context as well as the temporalities of others. From a more critical perspective, it could be argued that the opportunity to realize one's potential is a privilege that organizations reserve for those who are deemed valuable resources (i.e., so-called 'high-potential' employees). As such, organizational structures create inequalities, allowing a select group of elite employees to make progress towards the future by realizing their potential, while 'imprisoning' other employees in the present (Sharma, 2014). From this perspective, the routine and synchronization of time - characteristic of the experience of employees who feel they are not realizing their potential - can be seen as a social control mechanism (Bergmann, 1992). The question then becomes whether organizations are willing to create a space of opportunity for all employees to realize their potential and experience their work as meaningful.

\section{FUNDING INFORMATION}

This research was funded by an FWO Aspirant fellowship grant held by Giverny De Boeck (1166017N) and an OT grant from the KU Leuven held by Nicky Dries (DON-C6391-STRT/13/001).

\section{REFERENGES}

Albert, S. (1977). 'Temporal comparison theory'. Psychological Review, 84, 485-503.

Amabile, T. M., Barsade, S. G., Mueller, J. S. and Staw, B. M. (2005). 'Affect and creativity at work'. Administrative Science Quarterly, 50, 367-403.

Amabile, T. M. and Kramer, S. J. (2007). 'Inner Work Life'. Harvard Business Review, 85, 72-83.

Amabile, T. and Kramer, S. (2011). 'The power of small wins'. Harvard Business Review, 89, 70-80.

Arnold, K. A., Turner, N., Barling, J., Kelloway, E. K. and McKee, M. G. (2007). 'Transformational leadership and psychological well-being: the mediating role of meaningful work'. Fournal of Occupational Health Psychology, 12, 193-203.

Ashforth, B. E. and Kreiner, G. E. (1999). “How can you do it?”: dirty work and the challenge of constructing a positive identity'. Academy of Management Review, 24, 413-34.

Bailey, C. and Madden, A. (2016). 'What makes work meaningful - or meaningless'. MIT Sloan Management Review, 57, 53-61.

Bailey, C. and Madden, A. (2015). 'Time reclaimed: temporality and the experience of meaningful work'. Work, Employment \& Society, 31, 3-18.

Baumeister, R. F. and Vohs, K. D. (2002). 'The pursuit of meaningfulness in life'. In Snyder, C. R. and Lopez, S. J. (Eds), Handbook of Positive Psychology. New York: Oxford University Press, 608-18.

Baumeister, R. F., Vohs, K. D., Aaker, J. L. and Garbinsky, E. N. (2013). 'Some key differences between a happy life and a meaningful life'. The Journal of Positive Psychology, 8, 505-16. 
Berg, J. M., Grant, A. M. and Johnson, V. (2010). 'When callings are calling: crafting work and leisure in pursuit of unanswered occupational callings'. Organization Science, 21, 973-94.

Bergmann, W. (1992). 'The problem of time in sociology: an overview of the literature on the state of theory and research on the sociology of time, 1900-82'. Time \& Society, 1, 81-134.

Bodnar, I. (2012). Aristotle's Natural Philosophy. Available at: https://leibniz.stanford.edu/friends/preview/ aristotle-natphil/ (accessed 30 November 2016).

Bono, J. E. and Judge, T. A. (2003). 'Self-concordance at work: toward understanding the motivational effects of transformational leaders'. Academy of Management fournal, 46, 554-71.

Bosco, F. A., Aguinis, H., Singh, K., Field, J. G. and Pierce, C. A. (2015). 'Correlational effect size benchmarks'. Fournal of Applied Psychology, 100, 431-49.

Boswell, W. R., Boudreau, J. W. and Tichy, J. (2005). 'The relationship between employee job change and job satisfaction: the honeymoon-hangover effect'. Fournal of Applied Psychology, 90, 882-92.

Brendl, C. M. and Higgins, E. T. (1996). 'Principles of judging valence: what makes events positive or negative?'. Advances in Experimental Social Psychology, 28, 95-160.

Bunderson, J. S. and Thompson, J. A. (2009). 'The call of the wild: zookeepers, callings, and the double-edged sword of deeply meaningful work'. Administrative Science Quarterly, 54, 32-57.

Callero, P. L. (1985). 'Role-identity salience'. Social Psychology Quarterly, 48, 203-15.

Chalofsky, N. (2003). 'An emerging construct for meaningful work'. Human Resource Development International, 6, 69-83.

Clark, F. (1997). 'Reflections on the human as an occupational being: biological need, tempo and temporality'. Fournal of Occupational Science, 4, 86-92.

Cohen, S. M. (2016). Aristotle's Metaphysics. Available at: https://plato.stanford.edu/archives/win2016/entries/aristotle-metaphysics (accessed 23 December 2016).

Courtright, S. H., Colbert, A. E. and Choi, D. (2014). 'Fired up or burned out? How developmental challenge differentially impacts leader behavior'. Fournal of Applied Psychology, 99, 681-96.

Cross, S. and Markus, H. (1991). 'Possible selves across the life span'. Human Development, 34, 230-55.

Csikszentmihalyi, M. (2003). Good Business: Leadership, Flow and the Making of Meaning. New York: Viking.

Ekman, S. (2013). 'Fantasies about work as limitless potential - how managers and employees seduce each other through dynamics of mutual recognition'. Human Relations, 66, 1159-81.

Elsbach, K. D. (2003). 'Relating physical environment to self-categorizations: Identity threat and affirmation in a non-territorial office space'. Administrative Science Quarterly, 48, 622-54.

Fernando, M. and Chowdhury, R. M. (2015). 'Cultivation of virtuousness and self-actualization in the workplace'. In Sison, A., Beabout, G. and Ferrero, I. (Eds), Handbook of Virtue Ethics in Business and Management. Dordrecht: Springer, 805-16.

Fink, A. (2003). The Survey Handbook 1. Thousand Oaks, CA: Sage.

Fried, Y. and Ferris, G. R. (1987). 'The validity of the job characteristics model: a review and meta-analysis'. Personnel Psychology, 40, 287-322.

Frisby, C. L. and Braden, J. P. (1992). 'Feuerstein's dynamic assessment approach: a semantic, logical, and empirical critique'. The Fournal of Special Education, 26, 281-301.

Fuchs, C. and Diamantopoulos, A. (2009). 'Using single-item measures for construct measurement in management research: conceptual issues and application guidelines'. Die Betriebswirtschaft, 69, 195-210.

Grant, A. M. (2007). 'Relational job design and the motivation to make a prosocial difference'. Academy of Management Review, 32, 393-417.

Grouden, M. E. and Jose, P. E. (2014). 'How do sources of meaning in life vary according to demographic factors?'. New Zealand Fournal of Psychology, 43, 29-38.

Hackman, J. R. and Oldham, G. R. (1975). 'Development of the job diagnostic survey'. Fournal of Applied Psychology, 60, 159-70.

Higgins, E. T. (1987). 'Self-discrepancy: a theory relating self and affect'. Psychological Reviere, 94, 319-40.

Higgins, E. T. (2000). 'Making a good decision: value from fit'. American Psychologist, 55, 1217-30.

Hinchliffe, G. (2004). 'Work and human flourishing'. Educational Philosophy and Theory, 36, 535-47.

Hsieh, H. F. and Shannon, S. E. (2005). 'Three approaches to qualitative content analysis'. Qualitative Health Research, 15, 1277-88.

Humphrey, S. E., Nahrgang, J. D. and Morgeson, F. P. (2007). 'Integrating motivational, social, and contextual work design features: A meta-analytic summary and theoretical extension of the work design literature'. Fournal of Applied Psychology, 92, 1332-56.

Ibarra, H. (1999). 'Provisional selves: experimenting with image and identity in professional adaptation'. Administrative Science Quarterly, 44, 764-91. 
Idaszak, J. R. and Drasgow, F. (1987). 'A revision of the job diagnostic survey: elimination of a measurement artifact'. Fournal of Applied Psychology, 72, 69-74.

Kahn, W. A. (1990). 'Psychological conditions of personal engagement and disengagement at work'. Academy of Management Fournal, 33, 692-724.

Kamp, A., Lund, H. L. and Hvid, H. S. (2011). 'Negotiating time, meaning and identity in boundaryless work'. Fournal of Workplace Learning, 23, 229-42.

Kearney, R. (1988). 'Paul Ricoeur and the hermeneutic imagination'. Philosophy \& Social Criticism, 14, $115-45$.

Kovacs, G. (1982). 'The philosophy of death in Viktor E. Frankl'. Fournal of Phenomenological Psychology, 13, 197-209.

Kraimer, M. L., Seibert, S. E. and Liden, R. C. (1999). 'Psychological empowerment as a multidimensional construct: a test of construct validity'. Educational and Psychological Measurement, 59, 127-42.

Krippendorff, K. (2004). 'Reliability in content analysis'. Human Communication Research, 30, 411-33.

Kuo, A. (2011). 'A transactional view: occupation as a means to create experiences that matter'. Fournal of Occupational Science, 18, 131-38.

Leclerc, G., Lefrangois, R., Dube, M., Hebert, R. and Gaulin, P. (1998). 'The self-actualization concept: a content validation'. Fournal of Social Behavior and Personality, 13, 69-84.

Lips-Wiersma, M. and Morris, L. (2009). 'Discriminating between "meaningful work" and the "management of meaning"'. Fournal of Business Ethics, 88, 491-511.

Lu, C. Q., Wang, H. J., Lu, J. J., Du, D. Y. and Bakker, A. B. (2014). 'Does work engagement increase person-job fit? The role of job crafting and job insecurity'. Fournal of Vocational Behavior, 84, 142-52.

Maggetti, M., Radaelli, C. M. and Gilardi, F. (2012). 'Temporality'. In Maggetti, M., Radaelli, C. M. and Gilardi, F. (Eds), Designing Research in the Social Sciences. London: Sage, 93-114.

Markus, H. and Nurius, P. (1986). 'Possible selves'. American Psychologist, 41, 954-69.

Markus, H. and Wurf, E. (1987). 'The dynamic self-concept: a social psychological perspective'. Annual Review of Psychology, 38, 299-337.

Maslow, A. H. (1943). 'A theory of human motivation'. Psychological Review, 50, 370-96.

May, D. R., Gilson, R. L. and Harter, L. M. (2004). 'The psychological conditions of meaningfulness, safety and availability and the engagement of the human spirit at work'. Fournal of Occupational and Organizational Psychology, 77, 11-37.

McHugh, M. L. (2012). 'Interrater reliability: the kappa statistic'. Biochemia Medica, 22, 276-82.

Meister, A., Jehn, K. A. and Thatcher, S. M. (2014). 'Feeling misidentified: the consequences of internal identity asymmetries for individuals at work'. Academy of Management Review, 39, 488-512.

Michaelson, C., Pratt, M. G., Grant, A. M. and Dunn, G. P. (2014). 'Meaningful work: connecting business ethics and organization studies'. Fournal of Business Ethics, 121, 77-90.

Mitroff, I. and Denton, E. (1999). 'A study of spirituality in the workplace'. Sloan Management Review, 40, 83-92.

Mottaz, C. J. (1981). 'Some determinants of work alienation'. The Sociological Quarterly, 22, 515-29.

MOW International Research Team (1987). The Meaning of Working. New York: Academic Press.

Myers, D. G. (2009). Social Psychology, 10th edition. New York: McGraw-Hill Higher Education.

Nagy, M. S. (2002). 'Using a single-item approach to measure facet job satisfaction'. Fournal of Occupational and Organizational Psychology, 75, 77-86.

Nucci, L. (2004). 'Reflections on the moral self construct'. In Lapsley, D. and Narvaez, D. (Eds), Moral Development, Self, and Identity. Mahwah, NJ: Lawrence Erlbaum Associates Publishers, 111-32.

Oettingen, G. (2012). 'Future thought and behaviour change'. European Review of Social Psychology, 23, 1-63.

Oettingen, G., Marquardt, M. K. and Gollwitzer, P. M. (2012). 'Mental contrasting turns positive feedback on creative potential into successful performance'. Fournal of Experimental Social Psychology, 48, 990-96.

Oettingen, G., Pak, H. J. and Schnetter, K. (2001). 'Self-regulation of goal-setting: turning free fantasies about the future into binding goals'. Fournal of Personality and Social Psychology, 80, 736-53.

Olivier, A. L. and Rothmann, S. (2007). 'Antecedents of work engagement in a multinational company'. SA Fournal of Industrial Psychology, 33, 49-56.

Podsakoff, P. M., MacKenzie, S. B., Lee, J. Y. and Podsakoff, N. P. (2003). 'Common method biases in behavioral research: a critical review of the literature and recommended remedies'. Fournal of Applied Psychology, 88, 879-903. 
Pratt, M. G. and Ashforth, B. E. (2003). 'Fostering meaningfulness in working and at work'. In Cameron, K. S., Dutton, J. E. and Quinn, R. E. (Eds), Positive Organizational Scholarship: Foundations of a New Discipline. San Francisco, CA: Berrett-Koehler, 309-27.

Roe, R. A. (2008). "Time in applied psychology: the study of "what happens" rather than "what is"'. European Psychologist, 13, 37-52.

Rosso, B. D., Dekas, K. H. and Wrzesniewski, A. (2010). 'On the meaning of work: a theoretical integration and review'. Research in Organizational Behavior, 30, 91-127.

Ryff, G. D. (1991). 'Possible selves in adulthood and old age: a tale of shifting horizons'. Psychology and Aging, 6, $286-95$.

Schacht, R. (1971). Alienation. London: Allen and Unwin.

Scheffler, I. (2010). Of Human Potential: An Essay in the Philosophy of Education. New York: Routledge Revivals.

Schwartz, T. (2014). The Human Era@ Work: Findings from the Energy Project and Harvard Business Review. Available at: https://uli.org/wp-content/uploads/../The-Human-Era-at-Work.pdf (accessed 30 November 2016).

Shamir, B. (1991). 'Meaning, self and motivation in organizations'. Organization Studies, 12, 405-24.

Sharma, S. (2014). In the Meantime: Temporality and Cultural Politics. Durham, NG: Duke University Press.

Sheldon, K. M. and Elliot, A. J. (1999). 'Goal striving, need satisfaction, and longitudinal well-being: the self-concordance model'. Fournal of Personality and Social Psychology, 76, 482-97.

Shepherd, D. A. and Williams, T. A. (2018). 'Hitting rock bottom after job loss: bouncing back to create a new positive work identity'. Academy of Management Review, 43, 28-49.

Silzer, R. and Church, A. H. (2009). 'The potential for potential'. Industrial and Organizational Psychology, 2, 446-52.

Sonnentag, S. (2012). 'Time in organizational research: catching up on a long neglected topic in order to improve theory'. Organizational Psychology Review, 2, 361-68.

Spreitzer, G. M. (1995). 'Psychological empowerment in the workplace: dimensions, measurement, and validation'. Academy of Management Fournal, 38, 1442-65.

Spreitzer, G., Sutcliffe, K., Dutton, J., Sonenshein, S. and Grant, A. M. (2005). 'A socially embedded model of thriving at work'. Organization Science, 16, 537-49.

Steger, M. F. and Dik, B. J. (2009). 'If one is looking for meaning in life, does it help to find meaning in work?'. Applied Psychology: Health and Well-Being, 1, 303-20.

Stolorow, R. D. (2003). 'Trauma and temporality'. Psychoanalytic Psychology, 20, 158-61.

Strauss, K., Griffin, M. A. and Parker, S. K. (2012). 'Future work selves: how salient hoped-for identities motivate proactive career behaviors'. Fournal of Applied Psychology, 97, 580-98.

Stryker, S. and Burke, P. J. (2000). 'The past, present, and future of an identity theory'. Social Psychology Quarterly, 63, 284-97.

Taris, T. W. and Kompier, M. A. (2014). 'Cause and effect: optimizing the designs of longitudinal studies in occupational health psychology'. Work \& Stress, 28, 1-8.

Terkel, S. (1972). Working. New York: Pantheon.

Twenge, J. M., Catanese, K. R. and Baumeister, R. F. (2003). 'Social exclusion and the deconstructed state: time perception, meaninglessness, lethargy, lack of emotion, and self-awareness'. Fournal of Personality and Social Psychology, 85, 409-23.

Vanderbiesen, W. (2016). Vlaamse Arbeidsrekening. Raming van de bevolking naar socio-economische positie [The Flemish Labor Account: Charting the population according to socio-economic position]. Leuven: Flemish Policy Research Center for Work and Social Economy.

Vogt, C. P. (2005). 'Maximizing human potential: capabilities theory and the professional work environment'. Fournal of Business Ethics, 58, 111-23.

Waterman, A. S. (2004). 'Finding someone to be: studies on the role of intrinsic motivation in identity formation'. Identity, 4, 209-28.

Williams, E. F. and Gilovich, T. (2008). 'Conceptions of the self and others across time'. Personality and Social Psychology Bulletin, 34, 1037-46.

Williams, E. F., Gilovich, T. and Dunning, D. (2012). 'Being all that you can be: the weighting of potential in assessments of self and others'. Personality and Social Psychology Bulletin, 38, 143-54.

Wrzesniewski, A. and Dutton, J. E. (2001). 'Crafting a job: revisioning employees as active crafters of their work'. Academy of Management Review, 26, 179-201.

Wrzesniewski, A., Dutton, J. E. and Debebe, G. (2003). 'Interpersonal sensemaking and the meaning of work'. Research in Organizational Behavior, 25, 93-135. 